\title{
Development of an indirect ELISA for the detection of serum IgG antibodies against region IV of phase 1 flagellin of Salmonella enterica serovar Brandenburg in sheep
}

\author{
Kalyani Pererat and Alan Murray
}

Correspondence

Kalyani Perera

kalyani.perera@agresearch.co.nz

Received 6 February 2009

Accepted 13 August 2009
Institute of Veterinary, Animal and Biomedical Sciences, Massey University, Private Bag 11 222, Palmerston North, New Zealand

Region IV of phase 1 flagellin (FliC) of Salmonella enterica serovar Brandenburg

(S. Brandenburg) was expressed in Escherichia coli and purified by nickel chelate affinity chromatography. The purified recombinant protein was evaluated for its suitability as an antigen in an indirect ELISA for the detection of antibodies in sheep sera. A cut-off value of 0.1 was calculated using 80 serum samples collected from sheep with no previous history of $S$. Brandenburg. In the present study we show the results of ELISA with field sera collected from 81 sheep naturally infected with $S$. Brandenburg. The assay was able to detect antibodies belonging to the IgG class with a sensitivity of $93.8 \%$. Thus, indirect ELISA might be a suitable screening tool for serological monitoring of sheep flocks infected with $S$. Brandenburg.

\section{INTRODUCTION}

Salmonella enterica serovar Brandenburg (S. Brandenburg) has been a major cause of ovine abortions and mortality in New Zealand since 1996 (Clark, 2000; Clark et al., 2004; Roe, 1999; Smart, 2000). In addition, this pathogen infects humans through contact with infected animals and contaminated farming environments (Clark et al., 2004). Currently, diagnosis is carried out by standard bacteriological methods. When dealing with a large number of samples, a serological test such as ELISA is faster and cheaper than bacteriology (Funk et al., 2005; van Zijderveld et al., 1992). A number of ELISAs for detecting Salmonella antibodies have been described based on LPS (House et al., 2005; Veling et al., 2000) and flagellar (Dalby et al., 2005; Gast et al., 2002; Veling et al., 2000) antigens. These antigens result in a lack of specificity from cross-reactions among serotypes due to a sharing of somatic antigens of LPS and conserved terminal regions of flagellin (Cooper et al., 1989; Nicholas \& Cullen, 1991; Timoney et al., 1990).

Flagellins are highly immunogenic proteins and phase 1 flagellin is encoded by the fliC gene (Iino et al., 1988). Monomers are composed of conserved amino-terminal (regions I, II) and carboxy-terminal regions (region VIII), and a central variable region (regions III, IV, V, VI and VII) (de Vries et al., 1998; Wei \& Joys, 1985). Wei \& Joys

tPresent address: AgResearch, National Centre for Biosecurity and Infectious Disease, Wallaceville, PO Box 40063, Upper Hutt, New Zealand.

Abbreviation: AP, alkaline phosphatase.
(1985) showed that the predicted amino acid sequence of region IV showed less than $32 \%$ homology for any pairwise comparison of four different flagellins used in their study. Studies have shown that major serotype-specific flagellin antigenic determinants are located in region IV (de Vries et al., 1998; Newton et al., 1991).

Currently, recombinant proteins are used for the detection of serum antibodies in many bacterial diseases (Kwang \& Littledike, 1995). ELISAs using recombinant proteins containing phase 1 flagellin fragments for the detection of antibodies in poultry against $S$. enterica serotype Enteriditis have been reported (Mizumoto et al., 2004; Yap et al., 2001). To date, ELISAs based on recombinant flagellar antigens for the serodiagnosis of $S$. Brandenburg infection in sheep are not available. In this study, we first reacted sheep sera against recombinant region IV of phase 1 flagellin in Western blots to confirm the specificity of the binding, and then used the same antigen in an ELISA. This paper shows the results of an indirect ELISA for the detection of serum IgG antibodies against region IV of phase 1 flagellin in sheep naturally infected with $S$. Brandenburg.

\section{METHODS}

DNA extraction. $S$. Brandenburg field isolate S59 was obtained from the Microbiology Laboratory of the Institute of Veterinary, Animal \& Biomedical Sciences of Massey University, Palmerston North, New Zealand. Genomic DNA was extracted using a standard phenol/ chloroform method.

PCR and cloning. Genomic DNA was used as the PCR template. Two oligonucleotide primers containing restriction site NdeI 
(forward 5'-GGGAATTCCATATGAAGAGCGAAGCAGTTAAAAGCGG-3' and reverse 5'-GGGAATTCCATATGTTAAGCACTAATACCACTGTCGG-3') were designed to amplify a 369 bp fragment of region IV (nucleotides 544-912 bp) of the fliC gene (GenBank accession no. AY935580). The forward primer was designed to be inframe with the N-terminal histidine tag of the pET14b expression vector (Novagen). The amplified $400 \mathrm{bp}$ PCR product was digested with NdeI and cloned into pET14b using standard cloning techniques. Following transformation of Escherichia coli One Shot BL21 (DE3) competent cells (Life Technologies), plasmids were sequenced by the Sequencing Facility of Massey University to verify the reading frame and the sequence of the insert.

Expression and purification of recombinant protein. For protein expression, recombinant $E$. coli cells were grown on LB agar containing $50 \mu \mathrm{g}$ carbenicillin $\mathrm{ml}^{-1}$. A $5 \mathrm{ml}$ overnight LB culture originating from a single colony from the agar was inoculated into $500 \mathrm{ml} \mathrm{LB}$ and incubated at $37{ }^{\circ} \mathrm{C}$ until mid-exponential phase was reached. IPTG was added to a final concentration of $1 \mathrm{mM}$, and the culture was incubated at $37{ }^{\circ} \mathrm{C}$ for a further $3 \mathrm{~h}$. At the end of the $3 \mathrm{~h}$ incubation, the culture was pelleted by centrifugation.

The histidine-tagged fusion protein was found to be soluble, and purification was performed under native conditions using BD Talon metal affinity resin (Clontech Laboratories). Cell lysates of recombinant E. coli cultures were centrifuged at $10000 \mathrm{~g}$ for $30 \mathrm{~min}$ at $4{ }^{\circ} \mathrm{C}$, and the supernatant was used for protein purification according to manufacturer's instructions. The recombinant protein was eluted and collected in fractions of $1 \mathrm{ml}$ with elution buffer $\mathrm{pH} 7.0(50 \mathrm{mM}$ sodium phosphate, $500 \mathrm{mM}$ sodium chloride, $150 \mathrm{mM}$ imidazole). Fractions were analysed by SDS-PAGE, and those containing the purified protein were pooled and dialysed for $24 \mathrm{~h}$ against three changes of $41 \mathrm{PBS} \mathrm{pH}$ 7.4. Protein concentration was estimated using a Bio-Rad Protein assay kit (Bradford, 1976).

SDS-PAGE and Western immunoblotting. A modified Laemmli (1970) procedure was used to separate proteins on a discontinuous polyacrylamide gel consisting of a $4 \%$ stacking gel and a $12 \%$ separating gel. The proteins were transferred onto a PVDF membrane (Gelman Sciences), and the non-specific sites were blocked with $5 \%$ $(\mathrm{w} / \mathrm{v})$ skimmed milk powder in Tris-buffered saline $\mathrm{pH} 7.4$ supplemented with $0.1 \%(\mathrm{v} / \mathrm{v})$ Tween 20 overnight at $4{ }^{\circ} \mathrm{C}$. A preliminary Western blot was carried out to confirm the presence of histidine-tagged proteins post-purification. Subsequently, the membrane containing recombinant protein was cut into strips, and each strip was incubated with $10 \mathrm{ml}$ diluted sheep sera and with $10 \mathrm{ml}$ diluted alkaline phosphatase (AP)-labelled donkey anti-sheep whole IgG (Sigma) antibody. Each step was for $1 \mathrm{~h}$ at room temperature followed by a washing step. The strips were then incubated with $10 \mathrm{ml}$ phosphatase substrate, 5-bromo-4-chloro-3-indolylphosphate/nitro blue tetrazolium (Sigma), for colorimetric detection. Sera from a positive and a negative control sheep were included in each blot for comparison.

\section{Serum samples}

Samples were collected from three groups.

Group 1: sheep not exposed to S. Brandenburg. Sera were collected from 80 ewes in farms without a history of $S$. Brandenburg. These samples were used to determine the cut-off value in the ELISA. Faecal samples collected from these sheep were subjected to routine bacteriological procedures, and were negative for $S$. Brandenburg.

Group 2: sheep naturally infected with $S$. Brandenburg. Sera collected approximately 3-4 weeks post-abortion from $81 \mathrm{~S}$. Brandenburg-confirmed ewes were used in the ELISA. Vaginal swabs collected from these ewes were subjected to routine bacteriological procedures to confirm $S$. Brandenburg infection.

Group 3: sheep vaccinated with Salvexin and Salvexin + B. Salvexin vaccine (Schering-Plough Animal Health) contains inactivated $S$. enterica serovar Typhimurium (S. Typhimurium), S. enterica serovar Hindmarsh ( $S$. Hindmarsh) and S. enterica serovar Bovismorbificans, while Salvexin $+B$ vaccine contains inactivated $S$. Brandenburg in addition to the above three Salmonella serotypes. Sera collected from ewes that received Salvexin and Salvexin $+B$ were kindly provided by Dr Stanley Fenwick of Massey University, New Zealand, and used as a preliminary assessment of ELISA specificity. In this trial, 15 sheep were used as controls, 15 were vaccinated with Salvexin, and the other 15 were vaccinated with Salvexin $+B$. Ten samples collected prevaccination, and also at 2 weeks post-booster, from each group were used in the ELISA.

Indirect ELISA. Optimal concentrations of reagents were determined by chequerboard titrations (Crowther, 1995). Each well of 96-well MaxiSorp microtitre plates (Nunc) was coated with $100 \mu \mathrm{l}(2.5 \mu \mathrm{g}$ $\mathrm{ml}^{-1}$ ) recombinant protein in $0.1 \mathrm{M}$ bicarbonate buffer $\mathrm{pH} 9.6$ $\left(0.06 \mathrm{M} \mathrm{NaHCO}_{3}, 0.04 \mathrm{M} \mathrm{Na}_{2} \mathrm{CO}_{3}\right)$ for $2 \mathrm{~h}$ at $37{ }^{\circ} \mathrm{C}$. The plates were washed three times with PBS pH 7.4 containing $0.05 \%$ (v/v) Tween 20 , and once with PBS alone to remove unbound antigen. The nonspecific sites were blocked by incubation with $200 \mu$ PBS containing $5 \%(\mathrm{w} / \mathrm{v})$ skimmed milk powder per well for $1 \mathrm{~h}$ at $37{ }^{\circ} \mathrm{C}$, and washed. One hundred microlitres of sera diluted $(1: 100)$ in PBS containing $5 \%(\mathrm{w} / \mathrm{v})$ skimmed milk powder was added to each well in duplicate, and incubated for $1 \mathrm{~h}$ at $37^{\circ} \mathrm{C}$. After another cycle of washing, $100 \mu \mathrm{l} 1: 10000$ diluted AP-labelled donkey anti-sheep IgG was added to each well and incubated for $1 \mathrm{~h}$ at $37^{\circ} \mathrm{C}$. After a final series of washes, $100 \mu \mathrm{l}\left(1 \mathrm{mg} \mathrm{ml}^{-1}\right)$-nitrophenylphosphate (Sigma) dissolved freshly in $1 \mathrm{M}$ diethanolamine buffer $\mathrm{pH} 9.8,0.5 \mathrm{mM}$ $\mathrm{MgCl}_{2}$, was added to each well, and incubated for $30 \mathrm{~min}$ in the dark at room temperature. The resultant yellow colour reaction was stopped by the addition of $50 \mu \mathrm{l} 2 \mathrm{M} \mathrm{Na}_{2} \mathrm{CO}_{3}$ per well and the absorbance values at $405 \mathrm{~nm}\left(A_{405}\right)$ were determined using an ELISA plate reader (Molecular Devices). Negative control serum, positive control serum and dilution buffer were included on each plate. Each sample and control was assayed in duplicate. The cut-off value of the ELISA was determined as the mean absorbance of the 80 negative sera plus 3 SDs.

Statistical analysis. Excel (Microsoft) was used for basic calculations including means, SDs and SEMs. Results were analysed by Student's $t$-test (Excel; Microsoft) and considered significant when $P$ values were $<0.05$.

\section{RESULTS AND DISCUSSION}

SDS-PAGE, and the subsequent Western blotting of the purified $15 \mathrm{kDa}$ protein and analysis with anti-histidine $\mathrm{mAb}$ are shown in Fig. 1. None of the 80 sera collected from the non-infected group (group 1) contained antibody that recognized the purified protein. However, 81 of those sera collected from naturally infected sheep (group 2) reacted with it (Fig. 2, Table 1). All 10 sera from the Salvexin + B-vaccinated group reacted with the protein, but the 10 sera from the Salvexin group were non-reactive. All the pre-vaccination sera, and those collected from control sheep were negative in the blots (Table 1). The immunogenic characteristic of this recombinant flagellin elucidated by Western blots enabled the protein to be evaluated as a 
(a)

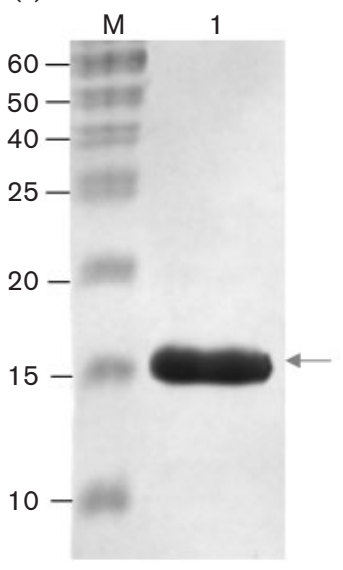

(b)

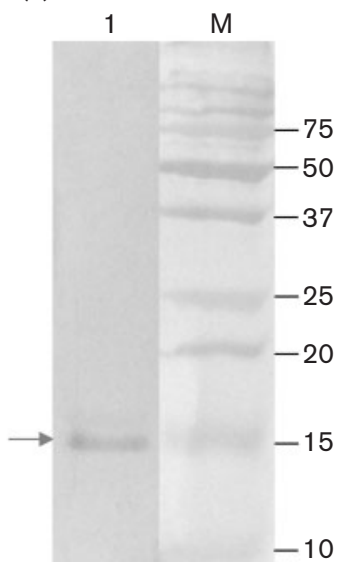

(a)
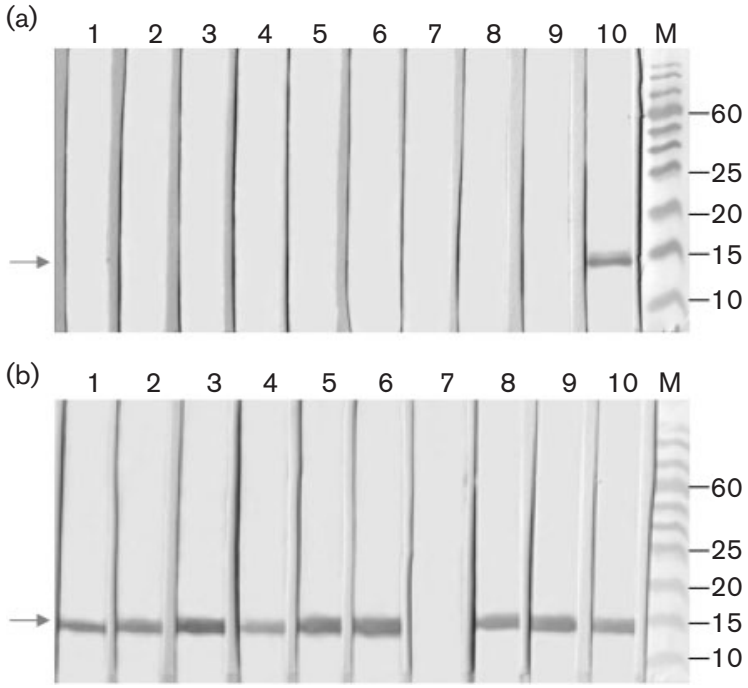

Fig. 1. (a) Purification of histidine-tagged recombinant protein by affinity chromatography. Sonicated cell lysate of $E$. coli was applied to a cobalt affinity column, and the bound protein was eluted with $150 \mathrm{mM}$ imidazole. A total of $5 \mu \mathrm{l}$ eluate was electrophoresed in a $12 \%$ SDS-PAGE gel, and stained with Coomassie blue. M, Prestained BenchMark protein ladder (kDa); 1 , purified recombinant protein. (b) Western blot detection of purified recombinant protein with anti-histidine $m A b$. A dilution of $1: 1000$ anti-histidine mouse $\lg \mathrm{mAb}$, and a 1:300 dilution of peroxidase-labelled sheep anti-mouse $\lg G$ were used. $M$, Precision Plus Protein dual colour standard $(\mathrm{kDa})$; 1 , purified recombinant protein. The arrows indicate the position of histidinetagged recombinant protein.

diagnostic antigen for incorporation into an ELISA for immunodetection of $S$. Brandenburg infection in sheep.

During optimization, chequerboard titrations indicated $250 \mathrm{ng}$ coating antigen, and a 1: 100 dilution of sheep sera should be used in the ELISA. The mean background absorbance of the ELISA was 0.08. The absorbance value of each sample was calculated by subtracting the background absorbance from the mean absorbance of the duplicates. All 80 sera collected from sheep not exposed to $S$. Brandenburg had absorbance values ranging from 0.002 to 0.070 . This population had a mean of 0.033 and an SD of 0.021 . The calculated cut-off value (mean plus 3 SDs of the absorbance values) from these 80 control sera was 0.096, and was set at 0.1 (data not shown).

Sera collected from the 81 sheep naturally infected with $S$. Brandenburg were used to evaluate the sensitivity of the ELISA. Sera with an absorbance value higher than 0.1 were scored as positive. Of the 81 sera, 76 were scored positive (Table 1). For these 81 samples, absorbance values ranged from 0.059 to 2.430 with a mean of 0.71 . Most had an absorbance in the range of $0.10-0.50$ (Table 2). Five of the samples that had absorbance values less than 0.1 were scored negative. Infection with Salmonella leads to increased levels of serum IgG antibodies (Withanage et al., 2005). This preliminary ELISA was carried out with sera
Fig. 2. Western blot detection of serum $\lg G$ antibodies against the recombinant protein in sheep naturally infected with $S$. Brandenburg. A 1:100 dilution of sheep sera, and a 1:10000 dilution of AP-labelled donkey anti-sheep $\lg G$ were used. (a) Lanes 1 to 8 , sera from sheep not exposed to $S$. Brandenburg (sample numbers N1, N8, N17, N23, N35, N52, N54, N60, respectively); lane 9, negative control; lane 10, positive control; $\mathrm{M}$, Prestained BenchMark protein ladder (kDa). (b) Lanes 1 to 6 , sera from sheep naturally infected with $S$. Brandenburg (sample numbers S7, S12, S2, S44, S9 and S11, respectively); lane 7, negative control; lane 8, positive control; lanes 9 and 10, sera from sheep naturally infected with $S$. Brandenburg (sample numbers S29 and S78, respectively); M, Prestained BenchMark protein ladder $(\mathrm{kDa})$. The arrows indicate the position of the recombinant protein.

from recently infected ewes (3-4 weeks post-abortion). Using a positive cut-off absorbance value of 0.1 , the ELISA correctly classified 76 out of 81 sheep naturally infected with $S$. Brandenburg as positive giving the assay a sensitivity of $93.8 \%$. The ELISA-negativity of the other five samples may be due to insufficient IgG at the time of sampling. The time interval between infection and blood sampling may have been too short for these five sheep to result in sufficient IgG levels to give an absorbance of 0.1 . The data provided indicate the potential usefulness of recombinant region IV protein in an ELISA to detect $S$. Brandenburg-infected sheep flocks in surveillance programs.

The use of sensitive methods for the identification of Salmonella is important because information on the true Salmonella status in sheep flocks is essential for the control of $S$. Brandenburg infection. Bacteriological culture is the 'gold standard' for Salmonella diagnosis, and is the only one that enables identification of the specific serovars. Although bacteriological culture methods are highly specific, there are disadvantages (Funk et al., 2005). Conventional bacteriological isolations from clinical sam- 
Table 1. Summary of serum IgG antibody detection of the recombinant protein in sheep by Western blot and indirect ELISA

\begin{tabular}{|c|c|c|c|c|}
\hline Source of samples (time of sample collection) & $\begin{array}{l}\text { No. of sera } \\
\text { tested }\end{array}$ & $\begin{array}{l}\text { No. of sera positive } \\
\text { in Western blot }\end{array}$ & $\begin{array}{c}\text { No. of sera } \\
\text { positive in ELISA }\end{array}$ & $\begin{array}{l}\text { Mean } A_{405} \\
\quad \text { (range) }\end{array}$ \\
\hline $\begin{array}{l}\text { Sheep naturally infected with } S \text {. Brandenburg (3-4 } \\
\text { weeks post-abortion) }\end{array}$ & 81 & 81 & 76 & $0.71(0.059-2.43)$ \\
\hline \multicolumn{5}{|l|}{ Sheep experimentally vaccinated with: } \\
\hline Salvexin & 10 & 0 & 0 & $0.03(0-0.06)$ \\
\hline Salvexin + B (2 weeks post-booster) & 10 & 10 & 10 & $0.72(0.28-1.82)$ \\
\hline
\end{tabular}

ples may not identify all infected animals due to the intermittent shedding of Salmonella. The actual shedding of Salmonella indicates true infection and transmission, whereas positive serology also indicates silent transmission within the flock (van Winsen et al., 2001). Therefore, serology can be used to identify infected and carrier animals, and to aid surveillance and epidemiological studies. However, the presence of serum antibodies will not discriminate between previous and current exposure, and between vaccination and natural exposure. A paired serum sample testing may be beneficial in this regard. In order to evaluate its suitability for detecting carriers, it will be necessary to determine for how long this ELISA remains able to detect antibodies in previously infected sheep. It is believed that the antibody response against Salmonella flagella is long lasting (Frimpong et al., 2000; Willke et al., 2002).

A preliminary assessment of ELISA specificity was carried out with sera collected from sheep vaccinated with Salvexin/Salvexin + B. Sera collected 2 weeks post-booster from ewes that received Salvexin and Salvexin $+B$ vaccines were used in the ELISA. Control sheep and sheep vaccinated with Salvexin had ELISA absorbance values less than 0.1 , whereas sheep vaccinated with Salvexin $+B$ had values more than 0.1 . For the latter group, values ranged from 0.28 to 1.82 with a mean of 0.72 (Fig. 3, Table 1). Only the sera from sheep vaccinated with Salvexin $+B$ were positive in the ELISA indicating the specificity of the assay.

Table 2. Detection of the serum lgG antibody response of naturally infected sheep against the recombinant protein by indirect ELISA

Sera collected 3-4 weeks post-abortion from 81 sheep naturally infected with $S$. Brandenburg were used at a dilution of $1: 100$.

\begin{tabular}{|lc|}
\hline $\boldsymbol{A}_{\mathbf{4 0 5}}$ range & No. of samples \\
\hline$<0.10$ & 5 \\
$0.10-0.50$ & 34 \\
$0.51-0.90$ & 13 \\
$0.91-1.30$ & 17 \\
$1.31-1.70$ & 6 \\
$1.71-2.10$ & 3 \\
$2.11-2.50$ & 3 \\
Total & 81 \\
\hline
\end{tabular}

However, studies with sera from sheep infected with other Salmonella serotypes and bacterial strains need to be performed to determine the true specificity of this ELISA. Non-availability of sera from sheep infected with other Salmonella serotypes at the time of the study was a limitation.

Serotype-specific flagellar antigenic determinants that are located in region IV of the FliC protein induce the production of serotype-specific antibodies in the infected host. Some of the serotype-specific flagellar antigens are composed of a single antigen (b, c, d, i, r) while others are composed of multiple antigens $(1, v ; 1, w ; e, h ; e, n, x ; e, n$, $\mathrm{z} 15 ; 1,2)$. Flagellar antigens are grouped into complexes depending on the antigens they share. Examples are the $\mathrm{E}$ complex that contains antigen e (e, h; e, n, x; e, n, z15) and the $\mathrm{L}$ complex that contains antigen $\mathrm{l}(\mathrm{l}, \mathrm{v} ; \mathrm{l}, \mathrm{w} ; \mathrm{l}, \mathrm{z} 13$; 1, z28). Phase 1 flagellin of $S$. Brandenburg belongs to the $\mathrm{L}$

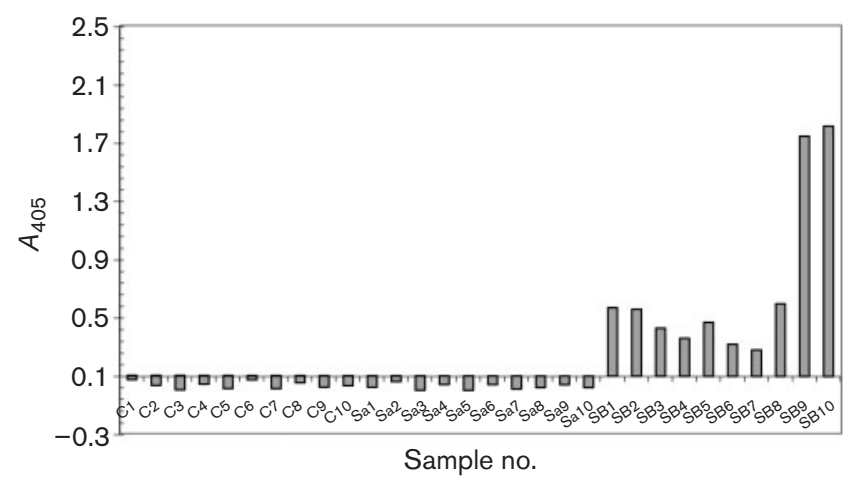

Fig. 3. Detection of $\lg G$ antibody response against the recombinant protein in sera from sheep vaccinated with Salvexin and Salvexin $+B$ by indirect ELISA. Sera collected 2 weeks postbooster from ewes that received Salvexin (sample numbers Sa1, $\mathrm{Sa} 2, \mathrm{Sa} 3, \mathrm{Sa} 4, \mathrm{Sa} 5, \mathrm{Sa} 6, \mathrm{Sa} 7, \mathrm{Sa}$, Sa9 and Sa10), Salvexin +B (sample numbers SB1, SB2, SB3, SB4, SB5, SB6, SB7, SB8, SB9 and SB10) and from ewes used as controls (C1, C2, C3, C4, $\mathrm{C} 5, \mathrm{C} 6, \mathrm{C} 7, \mathrm{C} 8, \mathrm{C} 9$ and $\mathrm{C} 10)$ were used. A serum dilution of $1: 100$ and $1: 10000$ dilution of AP-labelled donkey anti-sheep $\operatorname{lgG}$ were used. Each absorbance value represents the mean value of two determinations minus background absorbance. The cut-off value was set at 0.1 . A significant difference $(P<0.001)$ (Student's $t$ test) was found between the Salvexin- and Salvexin $+B-$ vaccinated groups. 
complex since it carries l, v epitopes. Salmonella serotypes that carry phase $1(\mathrm{H} 1)$ or phase $2(\mathrm{H} 2)$ flagellins belonging to the $\mathrm{L}$ complex would react with varying intensities in this ELISA due to shared epitopes among them. Examples of serotypes that possess $\mathrm{H} 1$ or $\mathrm{H} 2$ belonging to the $\mathrm{L}$ complex include Ayton (H1: l, w), Bredeney (H1: l, v), Give (H1: 1, v), Glidji (H1: 1, w), Gloucester (H2: 1, w), Kimberly (H1: l, v), Livingstone (H2: l, w), London (H1: l, v), Ohio $(\mathrm{H} 2: \mathrm{l}, \mathrm{w})$, Potsdam $(\mathrm{H} 1 \mathrm{l}, \mathrm{l}, \mathrm{v})$, Victoria $(\mathrm{H} 1 \mathrm{l}, \mathrm{l}, \mathrm{w})$ and Wien $(\mathrm{H} 2$ : 1, w). These serotypes are not common sheep pathogens and have not been shown to cause ovine abortions. However, it is advisable to complement positive ELISA results with history and bacteriological findings.

In Denmark, until the end of 1994, pigs were tested for salmonellosis exclusively by bacteriological methods. Since 1995, Salmonella testing is based on a combination of both bacteriological and serological methods (Skov et al., 2002). Currently, in Denmark, the screening of pigs for monitoring and controlling salmonellosis is by the identification of antibodies in serum and muscle juice (the juice released from small pieces of muscle frozen at $-20^{\circ} \mathrm{C}$ and thawed after 1-3 days) using an indirect ELISA with a mixture of flagellar LPS as coating antigens (Mousing et al., 1997). This program has reduced human cases of pork-related salmonellosis (Korsak et al., 2006). The purpose of this program is to identify common Salmonellae including $S$. Brandenburg without differentiating them. Since both $S$. Brandenburg and $S$. Typhimurium belong to serogroup B sharing LPS ' $O$ ' antigens 4 and 12, an LPS-based ELISA is not suitable to differentiate them. In New Zealand, $S$. Typhimurium and $S$. Hindmarsh are the most common causes of ovine salmonellosis, leading to diarrhoea and mortality with occasional abortions (Clark et al., 2002). S. enterica serovar Oranienburg has also been isolated from aborted fetuses in sporadic outbreaks of abortions in New Zealand (Russell \& Tannock, 1964). S. enterica serotypes Abortusovis, Dublin and Montevideo are causes of ovine abortions in other countries (Sharp et al., 1983; Wray \& Linklater, 2000). All these serotypes do not contain flagellar antigens of the L complex. Therefore, the ELISA described here would be able to differentiate $S$. Brandenburg from the above serotypes and this feature is important for disease monitoring purposes in New Zealand.

This is believed to be the first reported ELISA to detect seroconversion of $S$. Brandenburg-infected sheep using a recombinant Salmonella flagellin antigen. Recombinant flagellin proteins are easily produced through heterologous expression systems, and therefore can be obtained in large quantities that are relatively pure. Therefore, inclusion of a recombinant protein with region IV in coating ELISA plates rather than the whole flagellin isolated from cultures has advantages such as purity, low cost and noninfectiousness. Moreover, it increases the specificity of the assay due to the absence of cross-reactions caused by conserved regions of whole flagellin. In conclusion, the use of this ELISA in combination with clinical, bacteriological and/or molecular diagnostic methods would constitute an improved diagnostic assay for the detection of $S$. Brandenburg infection in sheep flocks.

\section{ACKNOWLEDGEMENTS}

We are thankful to Dr Stan Fenwick for providing us with serum samples from the vaccination trial he carried out at Massey University, and Jo Kerslake for kindly providing us with some of the sheep sera for this study. Kalyani Perera is grateful to Massey University for the doctoral scholarship. The authors thank Institute of Veterinary, Animal \& Biomedical Sciences, Massey University, postgraduate research fund, Lewis Fitch, and Morris and Paykel grant funds for providing financial assistance to carry out this study. Furthermore, thanks are given to Drs John Smart (Cluthavets Animal Health Centre, Balclutha, New Zealand) and Andrew Roe (Central Southland Veterinary Services, Winton, New Zealand) for collecting samples from sheep.

\section{REFERENCES}

Bradford, M. M. (1976). A rapid and sensitive method for the quantitation of microgram quantities of protein utilising the principle of protein-dye binding. Anal Biochem 72, 248-254.

Clark, G. (2000). Salmonella Brandenburg-update 2000. In Vetscript (December), pp. 16-17. Wellington: New Zealand Veterinary Association.

Clark, R. G., Robinson, R. A., Alley, M. R., Nicol, C. M., Hathaway, S. C. \& Marchant, R. M. (2002). Salmonella in animals in New Zealand: the past to the future. NZ Vet J $\mathbf{5 0}$ (Suppl.), 57-60.

Clark, R. G., Fenwick, S. G., Nicol, C. M., Marchant, R. M., Swanney, S., Gill, J. M., Holmes, J. D., Leyland, M. \& Davies, P. R. (2004). Salmonella Brandenburg - emergence of a new strain affecting stock and humans in the South Island of New Zealand. N Z Vet J 52, 26-36.

Cooper, G. L., Nicholas, R. A. \& Bracewell, C. D. (1989). Serological and bacteriological investigations of chickens from flocks naturally infected with Salmonella enteritidis. Vet Rec 125, 567-572.

Crowther, J. R. (1995). Methods in Molecular Biology: ELISA Theory and Practice. Totowa, NJ: Humana Press.

Dalby, T., Strid, M. A., Beyer, N. H., Blom, J., Mølbak, K. \& Krogfelt, K. A. (2005). Rapid decay of Salmonella flagella antibodies during human gastroenteritis: a follow up study. J Microbiol Methods 62, 233-243.

de Vries, N., Zwaagstra, K. A., Huis in't Veld, J. H. J., van Knapen, F., van Zijderveld, F. G. \& Kusters, J. G. (1998). Production of monoclonal antibodies specific for the $i$ and 1,2 flagellar antigens of Salmonella typhimurium and characterization of their respective epitopes. Appl Environ Microbiol 64, 5033-5038.

Frimpong, E. H., Feglo, P., Essel-Ahun, M. \& Addy, P. A. (2000). Determination of diagnostic Widal titres in Kumasi, Ghana. West Afr J Med 19, 34-38.

Funk, J. A., Harris, I. T. \& Davies, P. R. (2005). Comparison of fecal culture and Danish mix-ELISA for determination of Salmonella enterica subsp. enterica prevalence in growing swine. Vet Microbiol 107, 115-126.

Gast, R. K., Nasir, M. S., Jolley, M. E., Holt, P. S. \& Stone, H. D. (2002). Serologic detection of experimental Salmonella enteritidis infections in laying hens by fluorescence polarization and enzyme immunoassay. Avian Dis 46, 137-142.

House, D., Chinh, N. T., Diep, T. S., Parry, C. M., Wain, J., Dougan, G., White, N. J., Hien, T. T. \& Farrar, J. J. (2005). Use of paired serum samples for serodiagnosis of typhoid fever. J Clin Microbiol 43, 48894890 . 
lino, T., Komeda, Y., Kutsukake, K., Macnab, R. M., Matsumura, P., Parkinson, J. S., Simon, M. I. \& Yamaguchi, S. (1988). New unified nomenclature for the flagellar genes of Escherichia coli and Salmonella typhimurium. Microbiol Rev 52, 533-535.

Korsak, N., Degeye, J. N., Etienne, G., Beduin, J. M., China, B., Ghafir, Y. \& Daube, G. (2006). Use of a serological approach for prediction of Salmonella status in an integrated pig production system. Int J Food Microbiol 108, 246-254.

Kwang, J. \& Littledike, E. T. (1995). Production and identification of recombinant proteins of Salmonella Typhimurium and their use in detection of antibodies in experimentally challenged animals. FEMS Microbiol Lett 130, 25-30.

Laemmli, U. K. (1970). Cleavage of structural proteins during the assembly of the head of bacteriophage T4. Nature 227, 680-685.

Mizumoto, N., Toyota-Hanatani, Y., Sasai, K., Tani, H., Ekawa, T., Ohta, H. \& Baba, E. (2004). Detection of specific antibodies against deflagellated Salmonella Enteritidis and S. Enteritidis FliC-specific 9 kDa polypeptide. Vet Microbiol 99, 113-120.

Mousing, J., Jensen, P. T., Halgaard, C., Bager, F., Feld, N., Nielsen, B., Nielsen, J. P. \& Bech-Nielsen, S. (1997). Nation-wide Salmonella enterica surveillance and control in Danish slaughter swine herds. Prev Vet Med 29, 247-261.

Newton, S. M. C., Wasley, R. D., Wilson, A., Rosenberg, L. T., Miller, J. F. \& Stocker, B. A. (1991). Segment IV of a Salmonella flagellin gene specifies flagellar antigen epitopes. Mol Microbiol 5, 419-425.

Nicholas, R. A. J. \& Cullen, G. A. (1991). Development and application of an ELISA for detecting antibodies to Salmonella enteritidis in chicken flocks. Vet Rec 128, 74-76.

Roe, A. (1999). Salmonella Brandenburg: a practitioners perspective. In Proceedings of the 29th Annual Seminar of the Society of Sheep and Beef Cattle Veterinarians of the New Zealand Veterinary Association, 1st-3rd March 1999, Hastings, New Zealand, pp. 23-28.

Russell, R. R. \& Tannock, G. W. (1964). The isolation of Salmonella oranienburg from an ovine foetus in New Zealand. N Z Vet J 12, 25.

Sharp, J. C. M., Reilly, W. J., Linklater, K. A., Inglis, D. M., Johnston, W. S. \& Miller, J. K. (1983). Salmonella Montevideo infection in sheep and cattle in Scotland, 1970-1981. J Hyg (Lond) 90, 225-232.

Skov, M. N., Feld, N. C., Carstensen, B. \& Madsen, M. (2002). The serologic response to Salmonella Enteritidis and Salmonella Typhimurium in experimentally infected chickens, followed by an indirect lipopolysaccharide enzyme-linked immunosorbent assay and bacteriologic examinations through a one-year period. Avian Dis 46, 265-273.

Smart, J. A. (2000). Latest experiences of Salmonella Brandenburg. In Proceedings of the 30th Annual Seminar of the Society of Sheep and Beef Cattle Veterinarians of the New Zealand Veterinary Association, 1st3rd March 2000, Palmerston North, New Zealand, pp. 137-150.

Timoney, J. F., Sikora, N., Shivaprasad, H. L. \& Opitz, M. (1990). Detection of antibody to Salmonella enteritidis by a gm flagellin-based ELISA. Vet Rec 127, 168-169.

van Winsen, R. L., van Nes, A., Keuzenkamp, D., Urlings, H. A. P., Lipman, L. J. A., Biesterveld, S., Snijders, J. M. A., Verheijden, J. H. M. \& van Knapen, F. (2001). Monitoring of transmission of Salmonella enterica serovars in pigs using bacteriological and serological detection methods. Vet Microbiol 80, 267-274.

van Zijderveld, F. G., van Zijderveld-van Bemmel, A. M. \& Anakotta, J. (1992). Comparison of four different enzyme-linked immunosorbent assays for serological diagnosis of Salmonella enteritidis infections in experimentally infected chickens. J Clin Microbiol 30, 2560-2566.

Veling, J., van Zijderveld, F. G., van Zijderveld-van Bemmel, A. M., Barkema, H. W. \& Schukken, Y. H. (2000). Evaluation of three newly developed enzyme-linked immunosorbent assays and two agglutination tests for detecting Salmonella enterica subsp. enterica serovar Dublin infections in dairy cattle. J Clin Microbiol 38, 4402-4407.

Wei, L. N. \& Joys, T. M. (1985). Covalent structure of three phase-1 flagellar filament proteins of Salmonella. J Mol Biol 186, 791-803.

Willke, A., Ergonul, O. \& Bayar, B. (2002). Widal test in diagnosis of typhoid fever in Turkey. Clin Diagn Lab Immunol 9, 938-941.

Withanage, G. S. K., Wigley, P., Kaiser, P., Mastroeni, P., Brooks, H., Powers, C., Beal, R., Barrow, P., Maskell, D. \& McConnell, I. (2005). Cytokine and chemokine responses associated with clearance of a primary Salmonella enterica serovar Typhimurium infection in the chicken and in protective immunity to rechallenge. Infect Immun $\mathbf{7 3}$, 5173-5182.

Wray, C. \& Linklater, K. A. (2000). Salmonella infections in sheep. In Salmonella in Domestic Animals, pp 209-218. Edited by C. Wray \& A. Wray. London: CAB Publishing.

Yap, L. F., Low, S., Liu, W., Loh, H., Teo, T. P. \& Kwang, J. (2001). Detection and screening of Salmonella Enteritidis-infected chickens with recombinant flagellin. Avian Dis 45, 410-415. 